\title{
The Study of Growth of Calogaya sp. PLM8 on Cyrus the Great's Tomb, UNESCO World Heritage Site in Iran
}

\author{
Mahnaz Gholipour-Shahraki, Parisa Mohammadi* \\ Department of Microbiology, Faculty of Biological SciencesAlzahra UniversityTehranIslamic Republic \\ of Iran
}

\begin{abstract}
The tomb of Cyrus the Great, the most important monument in Pasargadae, has been listed as a world heritage site by UNESCO. Like many other stone monuments, the tomb has been affected by the colonization of microbial communities, especially lichens that were subjected to physical elimination in 2006. In the present study, recolonization of Calogaya sp. PLM8, a crustose lichen and its role in biodeterioration of Cyrus the Great tomb have been evaluated. Calogaya sp. PLM8 commonly colonized on this monument with significant distribution in the different facades. The interface of Calogaya sp. PLM8 with the underlying substrate has been investigated using the periodic acid-Schiff staining, scanning electron microscopy and energy-dispersive spectroscopy techniques. The results showed that both colonization of the lichen on the surface and symbiont cells penetration into the stone had caused extensive physical and chemical biodeterioration of the substrate. Besides the presence of the symbionts in the endolithic niches, other lithobiont microorganisms have been detected inside the stones. The presence of these endolithic microorganisms seems to be conditioned by the presence of the epilithic lichen thallus and its effects on the formation of microenvironments in the colonized stone. The lithobiont communities interact both geophysically and geochemically with the lithic substrate, inducing biodeterioration alteration in the tomb of Cyrus the Great.
\end{abstract}

Keywords: Cyrus the Great tomb, Biodeterioration, Lichen, Endoliths, Calogaya sp. PLM8 